\title{
Sentidos atribuídos por professores e por professoras sobre a atuação do coordenador pedagógico na formação continuada centrada na escola
}

\author{
Meanings attributed by teachers about the role of the pedagogical coordinator in a \\ school-centered continuing education \\ (iD) Lindinalva Ferreira de Queiroz \\ Universidade Federal de Pernambuco UFPE / Centro Acadêmico do Agreste - CAA - Caruaru-PE / Brasil \\ Mestra em Educação Contemporânea pela Universidade Federal de Pernambuco - UFPE / Centro \\ Acadêmico do Agreste - CAA - Caruaru-PE / Brasil \\ Graduada em História FAINTIVISA - PE/ Brasil. \\ Especialista em História do Nordeste FAINTIVISA - PE/ Brasil. \\ Especialista em Coordenação Pedagógica - UFPE / Brasil \\ Especialista em Psicopedagogia com Aperfeiçoamento e \\ Extensão Psicopedagogia e Clínica - UNIFACOL-PE/Brasil \\ Docente do Curso de Pedagogia/Pós-Graduação - UNIFACOL-PE/Brasil \\ Educadora de Apoio - Rede Estadual de Pernambuco /Brasil \\ Técnica Educacional - SEDUC/Escada-PE / Brasil \\ lindyqueiroz@yahoo.com.br
}

(D) Carla Patrícia Acioli Lins Universidade Federal de Pernambuco UFPE / Centro Acadêmico do Agreste - CAA - Caruaru-PE / Brasil Doutora em Sociologia pela Universidade Federal de Pernambuco -UFPE / Brasil Professora Associada da Licenciatura em Pedagogia e do Programa de Pós-Graduação em Educação Contemporânea. aciolilins.carla@gmail.com

\begin{abstract}
Resumo: Este artigo tem como objetivo analisar os sentidos que emergem do discurso de professores e professoras em processo de formação continuada centrada na escola sobre os saberesfazeres do coordenador pedagógico. Utilizamos como caminho metodológico a Análise do Discurso na perspectiva utilizada por Orlandi. Os dados foram construídos a partir da utilização de entrevistas semiestruturadas realizadas com nove professores do ensino médio da rede estadual de ensino do município de Vitória de Santo Antão (PE). Os achados da pesquisa revelam sobretudo que os sentidos sobre os saberesfazeres do/a coordenador/a pedagógico/a se articulam, principalmente, à lógica gerencialista e da performatividade afetando intensamente o cotidiano das escolas e os modos de ser e estar docente.
\end{abstract}

Palavras-chave: Sentidos. Formação continuada centrada na escola. Professores/as. Coordenador pedagógico.

Abstract: This article aims to analyze the meanings that emerge from the discourse of teachers in the process of continuing education in a school-centered context about the pedagogical coordinator's knowhow. We used as a methodological way the Speech Analysis in the perspective used by Orlandi. The data 
were built from the use of semi-structured interviews conducted with nine high school teachers from the state school system of the city of Vitória de Santo Antão (PE, Brazil). The findings of the research reveal above all that the meanings about the pedagogical coordinator's know-how are articulated, mainly, to the managerialist logic and the performativity, intensely affecting the daily life of the schools and the ways of being and being teachers.

Keywords: Meanings. School-centered education. Teachers. Pedagogical Coordinator.

\section{Introdução}

Este artigo se constituiu a partir de nossa pesquisa de mestrado e objetiva problematizar os sentidos que emergem do discurso dos/as professores/as em processo de formação continuada centrada na escola sobre os saberesfazeres do/a coordenador/a pedagógico/a. Este debate está situado no campo da formação continuada de professores ao buscar compreender o trabalho da coordenação pedagógica a partir dos sentidos atribuídos por professores e professoras, com quem e para quem, a coordenação pensa e desenvolve seus saberesfazeres no espaço tempo da formação continuada, especialmente a centrada na escola, temática relevante para o debate acerca da qualidade da educação escolar na medida em que no, contexto educacional atual, no qual a formação de professores e professoras vem se destacando como um tema crucial e de grande relevância na conjuntura das políticas públicas para a educação, os desafios apresentados à escola exigem do trabalho educativo profissionais que se comprometam, cotidianamente, com um processo de ensinoaprendizagem e que possam, também cotidianamente, empenhar-se em garantir uma aprendizagem significativa.

Em nossa perspectiva, a escola é pensada como território potente para essa modalidade de formação, posto que é, especialmente, na escola onde o professorado e a coordenação pedagógica, em relações educativas e de ensino aprendizagens com os estudantes, com seus pares e com a comunidade em geral, têm a possibilidade de pensar, (re)criar, inventar e organizar vivências e experiências, na maioria das vezes, atravessadas pelas imprevisibilidades dos acontecimentos do cotidiano escolar. Acontecimentos que provocam, que mobilizam professores/as e coordenação pedagógica a pensar sobre os fazeres/saberes que orientam e envolvem as práticas pedagógicas e educativas vividas e experienciadas na escola, especialmente, por esses/as atores/as. 
Assim, na escola, os/as professores/as estão imersos em possibilidades diversas de formação que podem se dar criativamente considerando a imprevisibilidade desse cotidiano. Dessa forma, a formação que se dá na e com a escola é potente no sentido de oferecer contribuições à valorização do estar e ser professor/a através justamente dessa diversidade de experiências formativas, incluindo as experiências que exploram a dimensão coletiva das aprendizagens sobre serestar professor, que podem potencializar saberes/fazeres, tanto do professorado quanto do/a coordenador/a pedagógico/a. Nesta perspectiva, buscamos compreender o trabalho desenvolvido pela coordenação pedagógica de formação continuada de professores/as a partir dos sentidos elaborados pelo professorado.

A formação centrada na escola, também entendida como formação em serviço (IMBERNÓN, 2011; SILVA, 2013), é mais que uma simples mudança de lugar, pois representa a criação e o reconhecimento de um espaço para o desenvolvimento de experiências e vivências formativas que possam levar em conta a autonomia e os saberesfazeres do coletivo de professores/as, passando a ser caracterizada como espaço de estudo e de desenvolvimento das potencialidades profissionais e humanas inerentes ao trabalho docente. É desta perspectiva que a escola emerge como lócus importante da formação de professores/as na busca por qualificar as práticas pedagógicas e educativas que se desenvolvem no cotidiano escolar, uma vez que a formação continuada centrada na escola considera as aprendizagens com os pares, no contexto de trabalho, mobilizadas por reflexões, realizadas coletivamente, bem como valoriza as práticas desenvolvidas na escola como importantes para o coletivo docente pensar sobre seus saberesfazeres.

Consideramos que esses movimentos, que podem mobilizar reflexões, expandem a perspectiva do trabalho individual realizado na sala de aula para uma visão potente do trabalho desenvolvido pela e na coletividade. É neste sentido que a escola passa a ser concebida como um espaço-tempo vivido coletivamente, como "uma instância relacional, dialógica" (MENDES, 2016), traduzindo-se no desenvolvimento de uma organização pedagógica que contribui não só com o desenvolvimento de aprendizagens mais significativas, mas, certamente, que também contribuirá para mobilizar e manter o gosto e o prazer por aprender.

Nesse contexto, ocupando lugar de ator importante no processo de formação que se desenvolve no espaço escolar e constituindo-se como um mediador importante das práticas pedagógicas e educativas nesse espaço, encontra-se o/a coordenador/a pedagógico/a, cujo caráter coletivo de seu envolvimento nas práticas desenvolvidas na escola reafirmamos. 
Sem a pretensão de apresentar o/a coordenador/a pedagógico/a como único ou principal agente das ações pedagógicas no contexto escolar, tampouco apresentá-lo/a como o "vilão de todas as mazelas que povoam o espaço intraescolar" (FACCI, 2004, p. 21), concebemos a coordenação pedagógica como um espaço discursivo, constituído de marcas sociais, ideológicas e históricas, que se apresenta carregado de tensões, ambiguidades, conflitos e contradições, mas que também se constitui como instância de mediação, sendo o contexto da formação continuada centrada na escola, a priori, o espaço-tempo de materialização dessa mediação, entendida aqui na perspectiva abordada por Placco (2002, p. 95) - "a reflexão e os questionamentos do professor quanto à sua prática pedagógica se encontram e se confrontam com os questionamentos e fundamentos teóricos evocados pelo Coordenador Pedagógico Educacional, num movimento em que ambos se formam e se transformam". Desse modo, evoca-se o processo formativo de ambos: professor/professora e do/a coordenador/a pedagógico/a.

Considerando o exposto acima, e alinhados com Rangel (2006), buscamos dar vez e voz aos profissionais envolvidos na formação continuada - não simplesmente no intuito de fazer uma consulta, pois concebemos ser importante que os/as professores/as tivessem condições de dizer e de se fazer escutar, pressupondo-se a existência de um contexto de fala articulada, uma fala possível de revelar a dimensão do trabalho pedagógico desenvolvido pela coordenação pedagógica na escola.

Para desenvolvermos o objetivo proposto neste artigo, recorremos aos estudos de Placco e Almeida (2012, 2015) e de Domingues (2014), a fim de discutirmos sobre a coordenação pedagógica; para pensarmos a formação continuada, buscamos dialogar com Imbernón (2011) e Silva (2013); e, por fim, tomamos o conceito de Análise de Discurso ${ }^{1}$ de Orlandi (2013) de forma a nos dar apoio metodológico.

Traçamos o percurso do trabalho de campo considerando o entendimento da própria Secretaria de Educação do Estado de Pernambuco de que "professor se faz na escola" (PERNAMBUCO, 2014, p. 29). Assim, fundamentamos a escolha das escolas no dispositivo da A.D., o interdiscurso, considerando sua ligação com a memória, pois, para Orlandi (2013), a memória também constitui o discurso, logo, o modo como ela emerge induz às condições de produção do discurso, o que nos permite remeter a toda uma filiação de dizeres, a uma memória e à identificação de sua historicidade. Assim, adotamos duas escolas da rede estadual do município de Vitória de Santo Antão (PE), a mais antiga e a mais recente, que foram identificadas como Escola 1 e Escola 2. A escolha do município se justifica por sediar a Gerência Regional de Educação (GRE) da Mata Centro, espaço que já conhecíamos e no qual pudemos observar a 
existência de um acompanhamento efetivo, por parte da GRE, tanto da realização das formações continuadas que aconteciam na escola, mesmo que ainda de forma muito prescritiva, quanto da atuação do coordenador pedagógico.

Para gerar nossos dados, optamos por realizar entrevistas semiestruturadas. Realizamos entrevistas com nove professores/as, sendo quatro da Escola 1 e cinco da Escola 2. A partir das entrevistas, chegamos às produções discursivas que nos possibilitaram identificar os sentidos que emergiram dos discursos dos/as professores/as em processo de formação continuada centrada na escola sobre a atuação do coordenador pedagógico.

Ao lançarmos nosso olhar para às produções discursivas do professorado, observamos a emergência de categorias relacionadas aos sentidos elaborados pelos/as professores/as em formação continuada acerca dos saberesfazeres da coordenação pedagógica. Tais sentidos são apresentados no tópico a seguir, que abriga os nossos achados: sentidos de saberesfazeres atravessados pelo gerencialismo e performatividade; o sentido de coordenação pedagógica articulado às relações interpessoais e um discurso que se movimenta entre o reconhecimento e a resistência ao trabalho da coordenação pedagógica.

\section{Movimentos discursivos de professores/as sobre os sentidos dos saberesfazeres do coordenador pedagógico na formação continuada centrada na escola}

Considerando-se as posições discursivas ${ }^{2}$ dos professores e professoras que colaboraram com a pesquisa, enfatizamos os enunciados mais recorrentes presentes em seus discursos. No entanto, respeitando-se as especificidades de cada sujeito em função de suas posições discursivas, também acolhemos em nossas análises enunciados menos recursivos por estarem enredados em uma mesma formação discursiva, sendo esta o lugar de constituição do sentido, bem como da identificação do sujeito, espaço no qual ele adquire identidade.

Nessa direção, tais pressupostos dialogam efetivamente com nossos achados na medida em que nos permitem pensar sobre os enunciados, bem como refletir acerca das regras que estabelecem as condições de existência, as produções na história, nos direcionando a compreender quais correlações podem ser estabelecidas com outros enunciados, buscando-se revelar qual papel reverbera-se neste jogo enunciativo, evidenciando-se os efeitos de sentidos que emergem desse contexto.

O dizer está ligado às suas condições de produção, havendo um vínculo constitutivo ligando-o à sua exterioridade. Percebemos nos enunciados de professores e professoras que a coordenação pedagógica constitui-se como um campo de atuação multifacetado, no qual o 
coordenador pedagógico carece de estar a serviço da ação docente procurando aproximar-se dos/as professores/as, demandando esforços para superar os entraves que muitas vezes apresentam-se nessa relação.

Não basta a escola ter um coordenador, é imprescindível que ele seja atuante, responsável, assumindo suas atribuições com vista a colaborar para a efetivação do processo de ensinoaprendizagem. Indo além do que está visível nos enunciados, as questões gerais do próprio sistema revelam um silêncio acerca da política educacional de performatividade e gerencialismo que sustenta a educação na rede estadual de Pernambuco. Conforme apontam Duarte e Oliveira (2014, p. 88), “[...] o(a) docente deixa de ter controle sobre seu próprio modo de ensino, atuando performativamente na transmissão de conteúdos previamente estabelecidos pelas avaliações padronizadas".

Concebendo-se o neoliberalismo como "um instrumento da política hegemônica do mundo capitalista, e que se encontra a serviço do mercado" (MIZIARA et al., 2015, p. 268), na rede estadual de Pernambuco o coordenador pedagógico vem cada dia mais sendo envolvido nas tramas das políticas educacionais de cunho neoliberal que esse estado vem assumindo nas últimas décadas, em muitos casos, deixando tal profissional refém de uma postura que muitas vezes vai na contramão daquilo em que ele acredita enquanto educação, deixando-o cada vez mais à mercê do poder que emana dessas políticas.

O combate a essa política requer dos coordenadores pedagógicos uma visão crítica para conseguirem rejeitar as formações oferecidas de maneiras aligeiradas, fragmentadas, descontínuas utilizadas para fins de alienação, produção, reprodução do pensamento hegemônico (MIZIARA et al., 2015, p. 268).

Essa política do governo vem causando inquietação e, por que não dizer, indignação no meio educacional do estado de Pernambuco, que, em detrimento de uma educação de qualidade, vem inserindo cada vez mais as escolas numa esquizofrenia institucional, em busca de ranking.

Discussão essa que reverbera na eficácia e eficiência no âmbito da atuação da coordenação pedagógica, pois os discursos enunciados vêm nos revelando que muitas vezes o coordenador tem a sua função, "sabe o que é que deve fazer, mas, por conta do ambiente ou por conta da direção, termina desviando o caminho". Afirmando-se que isso se torna um desvio de função, o discurso alerta sobre os riscos que a escola corre de não avançar positivamente em seu processo ao proferir que "quando há este desvio você sabe que aí já vai haver uma alteração em tudo, não vai ter um procedimento tão positivo", pois as emergências vão atropelando e fragmentando as ações cotidianas que estão imbricadas nas condições oferecidas pela escola. 
No entanto, os discursos nos revelam um não dito, que seria pensar esse desvio como um descuido do coordenador pedagógico sobre a essência de suas atribuições, por envolver-se nas tramas das atividades, que podemos entender como secundárias em sua atuação, e deixando claro que não sabem as fronteiras dessa atuação, de seu papel. E isso, frente às imposições, tanto internas como externas, o leva a fazer o que entende pertencer à sua esfera de responsabilidades, de competência.

Percebe-se, assim, uma perspectiva tecnicista nos processos de formação continuada que apontam resultados de cunho gerencialista em que se conjetura a tecnização do ensino como uma predominância das políticas educacionais, o que efetivamente não promove uma autonomia profissional. O modelo gerencialista revela dificuldades do sistema público de ensino em lidar com a melhoria da qualidade e a eficiência dos resultados, atribuindo aos/às professores/as a posição discursiva de técnico, relegando o ensino a um processo de cumprimento de metas estabelecidas no gerencialismo.

\section{Sentidos de saberesfazeres atravessados pelo gerencialismo e performatividade}

Tomando o neoliberalismo como "um instrumento da política hegemônica do mundo capitalista, e que se encontra a serviço do mercado" (MIZIARA et al., 2015, p. 268), na rede estadual de Pernambuco, o coordenador pedagógico tem sido envolvido nas políticas educacionais de cunho neoliberal que o estado vem assumindo nas últimas décadas, em muitos casos, pondo-o em conflito por se ver assumindo uma postura que, muitas vezes, é contrária ao que acredita ser o exercício de sua função. Assim sendo, em nome de uma educação escolar pública e de qualidade, a política de cunho neoliberal na rede estadual de Pernambuco tem enfatizado o discurso da eficácia, da gestão gerencial das escolas, da avaliação de desempenho da rede, do professorado e dos estudantes, entre outros exemplos, impactando nos modos de ser e estar coordenador pedagógico. É importante salientar que o discurso da eficiência e eficácia se articula em sua produção ao discurso da performatividade, uma vez que, segundo essa lógica, uma escola reconhecida de qualidade é uma escola que alcança bons resultados nas avaliações externas e certamente tem a organização de seu trabalho pedagógico mediada pela coordenação, orientada também na direção do que se espera de uma escola concebida de qualidade, considerando a política adotada pela rede. Nesse caso, ao se aproximar de uma perspectiva gerencial e performativa, o trabalho da coordenação pedagógica se distancia dos saberesfazeres que consideram sua atuação importante referência na formação continuada do professorado ou 
da função de acompanhamento pedagógico do trabalho escolar envolvendo a atenção às diferenças e demandas existentes tanto entre professores/as quanto entre estudantes, apenas para citar um exemplo.

Em referência, por exemplo, à posição em que o estado de Pernambuco passou a ocupar no ranking nacional ${ }^{3}$, professorado e coordenação duvidam da posição ocupada nacionalmente quando, um professor, por exemplo, enuncia que “[...] O estado de Pernambuco está acima dos outros estados, mas, na realidade, pra mim [...] isso é só uma questão de números [...]”. Seu discurso ilustra as tensões e os questionamentos que atravessam os saberesfazeres tanto de professores/as quanto da coordenação pedagógica, pois os números e a posição do estado no ranking ocultam o trabalho pedagógico que se desenvolve na escola, suas dificuldades, as experiências pedagógicas e didáticas bem-sucedidas, as aprendizagens dos estudantes, a organização do trabalho escolar e pedagógico, ou seja, o pertencimento ao ranking nada traduz sobre a vida que acontece na escola. Esse dizer também revela as muitas inquietações que a política educacional baseada na performatividade tem causado nos sujeitos envolvidos no e pelo cotidiano escolar marcado por ações políticas performativas.

Pudemos perceber que esses discursos afetam a atuação da coordenação pedagógica, pois os enunciados revelam que o coordenador/a tem clareza sobre os saberesfazeres que ancoram seu exercício; ele "sabe o que é que deve fazer, mas, por conta do ambiente ou por conta da direção, termina desviando o caminho", aponta uma professora. Observamos que as tensões e pressões externas à coordenação podem estar se sobrepondo a uma atuação pautada nos saberesfazeres até aqui reconhecidos como da coordenação pedagógica. Os discursos apontam também que as tensões e pressões postas pela busca de resultados considerados bons pela gestão gerencial da Secretaria de Educação vão impondo um cotidiano de emergências que atropelam e fragmentam as ações da coordenação pedagógica, distanciando-a do trabalho junto ao professorado.

Reafirmamos que a performatividade, caracterizada, entre outros fatores, por atribuir ao indivíduo a responsabilidade pelo seu desenvolvimento através da produtividade, promove "[...] discursos de excelência, efetividade e qualidade, a lógica, e cultura do novo gerencialismo" (BALL, 2006, p. 12). Vimos que a performatividade e o gerencialismo emergem nos discursos dos/as professores/as na dimensão do não dito, quando uma professora, por exemplo, nos diz que “[...] o objetivo deles (Secretaria de Educação) é focar no resultado final [...]”. E continua nos enunciando que, por mais que o coordenador revele não concordar com essa política, “[...] eles têm que incentivar o professor a trabalhar de forma com que o aluno, de uma forma ou de outra, 
passe". Tais ações cotidianas por parte da coordenação pedagógica, forjadas em decorrência da adesão da rede estadual a políticas que privilegiam a performance, podem até alcançar os indicadores postos para as escolas e redes, mas qualitativamente produzem poucos impactos no que se referem aos processos de ensinoaprendizagem, por exemplo. Pudemos observar, mais uma vez, que a coordenação pedagógica tende, no contexto marcado pela performatividade, a se distanciar de sua função mediadora das práticas pedagógicas, e mesmo que resistindo, acaba exercendo importante papel na configuração da política performativa vivenciada na rede estadual, na medida em que, tendo como responsabilidade articular o trabalho pedagógico, que em si já guarda potencialidade formativa, e conduzir os momentos de formação continuada centrada na escola, acaba por colaborar com a materialização das políticas da rede.

$\mathrm{Na}$ materialização da política gerencialista e performativa, o coordenador desenvolve seu trabalho sob as orientações da Secretaria de Educação através das Regionais de Educação que predeterminam as pautas da formação de professores, distanciando-se dos objetivos e das potencialidades da formação centrada na escola, suprimindo a autonomia da escola e dos docentes, colaborando para firmar práticas gerencialistas na escola. A fala de uma professora torna evidente o gerencialismo vivido na rede, bem como o trabalho da coordenação pedagógica que tem sido opacificado em sua natureza criativa e em sua autonomia, ao enunciar que nas formações que acontecem na escola “[...] já vem o modelo pronto [...] não dá liberdade pra o coordenador fazer aquilo que ele acharia melhor, ele vai ser guiado por aquilo que ele tem que fazer, tem que ser assim".

Na sequência discursiva, também reverbera um não dito que traduz um sentido tecnicista, por suas características controladoras, mecânicas e repetitivas por parte da Secretaria de Educação ao não considerar o cotidiano das escolas no que se refere a suas problemáticas. Reverbera ainda um sentido de heteronomia pedagógica dos coordenadores pedagógicos frente ao processo de formação na escola, no que se refere às temáticas e à elaboração das formações que eles têm como responsabilidade precípua de desenvolver junto aos/às professores/as no contexto escolar. Torna-se claro que essa falta de autonomia interfere na prática pedagógica desenvolvida na escola, pois seu exercício, quando "condizente com as novas exigências educacionais, deve permitir, em primeiro lugar, a autonomia do coordenador pedagógico em inovar e repensar sua atuação de articulador das práticas educativas que visam à eficácia do processo de ensino e aprendizagem" (COSTA, 2015, p. 18). 
Mas como pensar/viver uma coordenação pedagógica na perspectiva da mediação, como um espaço em que se exerce a autonomia, se esta encontra-se atravessada por uma política educacional performativa sobre a qual Silva e Sampaio (2015, p. 971-972) afirmam:

\footnotetext{
O papel dos coordenadores pedagógicos torna-se ainda mais complexo, sendo estes obrigados a adaptar-se a um processo de regulação administrativa gerencial definida pelos órgãos centrais da burocracia estatal nacional e estadual que compreendem como parâmetros de qualidade educacional a melhoria de desempenho individual dos alunos nos testes nacionais de aferição de competências e habilidades cognitivas em áreas específicas do conhecimento, em geral Português e Matemática.
}

Ressaltamos que a preocupação criada nas escolas com o desempenho nas áreas específicas de Língua Portuguesa e Matemática faz parte da disputa por boa localização no ranking das melhores escolas, mesmo que os resultados não se constituam, necessariamente, em garantias de que houve aprendizagens significativas nessas disciplinas. Ao contrário, o ranqueamento acaba reduzindo o trabalho pedagógico e escolar ao controle administrativo, sem a preocupação com sua natureza e com os processos que podem conduzir a aprendizagens, tal como podemos verificar na fala da professora: "[...] passar todos não condiz com a realidade escolar [...] se o aluno é aprovado não quer dizer que ele conseguiu alcançar o objetivo, que era aprender, porque nós somos induzidos ou forçados a fazer com que o aluno passe de uma forma ou de outra”.

Nessa direção, os dizeres confirmam a presença do controle compondo a política educacional, que por sua vez evidencia uma preocupação, excessiva, com rankings, o que provoca competições entre as escolas da rede em nome da qualidade e da inovação, apesar de os professores reconhecerem que políticas assim “[...] querendo ou não, atrapalham o rumo, o andamento da escola e aí alguns coordenadores acabam se perdendo neste meio-tempo aî".

Diante do exposto, ressaltamos que, na cultura do desempenho, o coordenador tem à sua frente o desafio de propor intervenções que possam garantir o processo de ensinoaprendizagem para que as metas projetadas para a escola sejam cumpridas e atendam aos indicadores de sucesso preconizados pela cultura performativa, na qual a escola, através da política educacional da rede, está imersa, permitindo-nos inferir a existência de um sentido para os saberesfazeres do coordenador pedagógico: o de intermediador para o cumprimento das metas.

\section{$4 \mathrm{O}$ sentido de Coordenação Pedagógica articulado às relações interpessoais}

A coordenação pedagógica no desenvolvimento de suas atividades ancora-se em três dimensões (PLACCO; ALMEIDA, 2015, p. 10): articuladora, formadora e transformadora, 
cabendo ao coordenador pedagógico envolver os vários segmentos da escola de modo que possa mobilizar o sentimento de coletividade em torno do trabalho escolar. Apesar da condição de uma gestão gerencialista e performativa, percebemos que existe e ainda resiste um sentimento de coletividade, considerado parte do trabalho pedagógico, evidenciado no que é enunciado por uma professora ao afirmar que "[...] o resultado quando é em conjunto é bem melhor e bem mais gratificante [...]”. Tais enunciados nos permitem apontar para o caráter relacional da coordenação pedagógica, que se constitui, segundo André e Vieira (2012, p. 21), de "saberes humanos a respeito de seres humanos", caracterizando-se como saberes relacionais que contribuem com o trabalho desse profissional: a relação que estabelece com a comunidade escolar de maneira geral e especificamente com o professorado.

$\mathrm{Na}$ trama das formações discursivas, observamos recorrências nos enunciados, ao fazerem analogia da coordenação pedagógica metaforicamente como "ser ponte", conforme podemos conferir nas sequências discursivas postas por uma professora:

\begin{abstract}
Ser uma ponte, seria ligar a questão da docência em sala de aula com os afazeres do colégio em si, né? A estrutura, a dinâmica da escola, aonde [sic] ela seria uma espécie de facilitadora, ela ajudaria a gente, nesse caso mediar esses conflitos que existem em sala de aula, aluno, gestão, eh! Secretaria. Então, a coordenação eu acho que ela é uma ponte que ela liga esses elos aí, tentando aproximar ao máximo todos envolvidos no processo, mas também facilitar pra gente esses processos.
\end{abstract}

Nessa direção, partimos do princípio de que "pontes" são construções que objetivam transpor obstáculos para estabelecer a continuidade de uma via de qualquer natureza. As construções de tais pontes objetivam transpor os obstáculos que vêm impedindo a coordenação pedagógica de ser concebida como advoga Domingues (2014, p. 17): "uma prática intelectual que se modifica em decorrência do tempo histórico, das mudanças sociais e políticas e das experiências vivenciadas pelos educadores no contexto educativo". É imprescindível lembrar que para exercer a coordenação pedagógica, não só na história da educação brasileira, como na história de outros países, principalmente nos momentos de implementação de reformas educacionais, sempre se pensou na figura de um profissional capaz de acompanhar as mudanças a que naturalmente as escolas são submetidas (PLACCO; ALMEIDA, 2012).

Os dizeres do professorado acerca da coordenação pedagógica apontam um movimento discursivo que parece também revelar um não dito: a redução da atuação da coordenação apenas à função articuladora das relações interpessoais no contexto escolar. Este sentido firmado entre o professorado pode acabar fortalecendo o controle burocrático e administrativo sobre o trabalho pedagógico da escola e de mediação da coordenação. 
Enfatizamos, a partir de Ramos e Waterkemper (2013), o coordenador pedagógico como mediador das relações interpessoais no contexto escolar, no sentido de favorecer o seu fortalecimento, facilitar as discussões e tomadas de decisões quando ocorrem conflitos no cotidiano escolar, pois sua atuação carece de voltar o olhar para ações que colaborem e estimulem a resolução de conflitos e potencializem as relações interpessoais.

Essas relações se constituem uma pequena ponta do iceberg que a coordenação representa, ela é isso, mas é muito mais, pois, ao ser revelado como ponte nos enunciados, convém ressaltar que será preciso avançar para uma concepção de coordenação para além da metáfora da ponte, para além das relações interpessoais.

Pensar a coordenação pedagógica para além das relações interpessoais é pensar em outros contornos no próprio movimento de sua atuação, estar para além da assistência didáticopedagógica de tal forma que se faça importante uma atuação que oportunize aos/às professores/as momentos de reflexões nos quais possam pensar acerca dos pontos positivos e negativos do seu processo docente, o que nos leva a perceber como não dito que essa avaliação é extensiva à atuação do coordenador quando enuncia "no andamento do processo".

Concebemos esse processo como via de mão dupla, ao entendermos que a coordenação pedagógica, como ação circunscrita no espaço físico escolar, constitui-se um espaço discursivo formado por posicionamentos distintos, no qual não cabem ações que não sejam permeadas por processos interativos, por reciprocidades, mas um espaço que se encontra sempre em movimento.

\section{Um discurso que se movimenta entre o reconhecimento e a resistência ao trabalho da Coordenação Pedagógica}

A coordenação pedagógica se constitui como um campo de atuação multifacetado no qual o coordenador pedagógico carece de estar a serviço da ação docente procurando aproximarse dos/as professores/as, demandando um esforço em superar os entraves que muitas vezes se apresentam nessa relação.

No espaço em que o coordenador pedagógico é mediador, observamos que os discursos dos/as professores/as revelaram um dito do qual emerge um sentido referente ao reconhecimento da importância da atuação desse profissional para o professorado e estudantes, porém também pudemos observar que os/as professores/as não se filiavam à possibilidade de ocupar a posição discursiva dos coordenadores, o que nos permitiu chegar a um sentido de resistência ao exercício da função de coordenação pedagógica. 
Percebemos o movimento de reconhecimento de sua atuação na defesa da importância dos papéis desenvolvidos pelo coordenador pedagógico. Nessa direção, uma professora enuncia: “[...] Eu digo que ele é essencial numa escola, uma escola não consegue funcionar bem se não existir o coordenador". Muito provavelmente ela fala de um coordenador que possa assumir suas atribuições, distanciado da lógica performativa e aproximado de práticas intencionais e articuladas com o que foi definido pela comunidade escolar e está posto no Projeto Político-Pedagógico da escola. Importa também salientar que o discurso acerca da coordenação pedagógica guarda críticas; esta mesma professora, quando interrogada como seria sua atuação caso fosse coordenadora, nos revela que o coordenador deve "[...] atuar mais juntamente com os/as professores/as, buscando as necessidades de cada um [...] E tentando ficar mais participativa com relação às necessidades dos alunos também".

Já o discurso da resistência à atuação da coordenação pedagógica parece se articular à intensificação do gerencialismo e da performatividade na rede estadual - o professorado sente-se cobrado, vigiado, fiscalizado e controlado, especialmente por sua atuação na formação continuada, que tem se reduzido, como afirmado anteriormente, às pautas postas pela Secretaria de Educação e que envolvem, sobretudo, o alcance de indicadores. Podemos confirmar essa resistência a partir do que é dito pela professora ao enunciar que: “Tem até alguns professores [...] eu já ouvi, de não gostar muito desta presença, é como se houvesse uma cobrança maior [...]”. Outra professora nos afirma que: "existe muita resistência por parte dos professores [...] Mesmo sendo trabalhado isto aí, mas a gente ainda percebe por parte de alguns colegas uma resistência muito grande".

Observamos que os discursos dos/as professores/as sobre os saberesfazeres da coordenação pedagógica, ao transitarem entre o reconhecimento e a resistência ao seu trabalho, também são atravessados pelo discurso do gerencialismo e da performatividade, pois a resistência do professorado se articula em torno do receio ao controle e cobranças excessivas ao seu trabalho. Tensionando na direção contrária, encontramos os sentidos que articulam o reconhecimento e a valorização dos saberesfazeres da coordenação pedagógica e que demandam por sua atuação orientada pelo acompanhamento à formação continuada e ao trabalho pedagógico da escola. Esse movimento entre reconhecimento e resistência aponta para a existência de disputa e busca por hegemonia de sentidos.

\section{Considerações Finais}


A análise discursiva não se fundamenta ausente à exterioridade que permeia toda produção do dizer, assim os sentidos emergiram dos discursos dos/as professores/as inseridos em um contexto de formação continuada centrada na escola, que concebemos como um espaço discursivo que se constitui um coro de vozes que ecoam de diferentes lugares e posições, não dependendo apenas de suas intenções, entendendo-se que os discursos trazem suas próprias especificidades em relação ao lugar no qual estão situados.

Os sentidos sobre os saberesfazeres do coordenador pedagógico se articulam, principalmente, à lógica gerencialista e da performatividade que tem afetado intensamente o cotidiano das escolas e os modos de ser e estar docentes, principalmente na escola pública através de modelos gerenciais que têm secundarizado a função da escola e sua natureza, bem como a docência. Pudemos verificar, por outro lado, que a coordenação pedagógica ainda porta sentidos relacionados à importância de sua função no contexto escolar. Tais sentidos adquirem também importante papel na resistência ao cotidiano marcado por tensões, principalmente, em torno do alcance dos indicadores na medida em que o professorado reconhece e atribui ao coordenador importante função articuladora do trabalho pedagógico.

Consideramos que ser coordenador/a pedagógico/a é estar aberto a novas aprendizagens que lhe possibilitarão atuar de forma assertiva e proativa no espaço escolar que carece que atitudes e posturas sejam condizentes com o que de fato ele representa, espaço de produção de conhecimentos, seu combustível e mola propulsora, espaço genuíno de sua atuação.

Nossas reflexões sobre a coordenação pedagógica indicam a necessidade de estudos e debates mais sistemáticos, principalmente em torno das mudanças que podem estar em curso nas suas práticas a partir das políticas educacionais com o objetivo de instituir na escola um modelo gerencial e performativo, inserindo cada vez mais o trabalhador num processo que é desenvolvido de tal forma que o profissional se envolve emocionalmente sem se dar conta de que está caindo na teia do emocionalismo instrumental ${ }^{4}$.

\section{Referências}

ANDRÉ, Marli Eliza Dalmazo Afonso de; VIEIRA, Marili M. da Silva. O coordenador pedagógico e as questões dos saberes. In: ALMEIDA, Laurinda Ramalho de; PLACCO, Vera Maria Nigro de Souza (org.). O coordenador Pedagógico e questões da contemporaneidade. 6. ed. São Paulo: Loyola, 2012.

BALL, Stephen J. Profissionalismo, gerencialismo e performatividade. Cadernos de Pesquisa, São Paulo, v. 35, n. 126, p. 539-564, set./dez. 2005. 
BALL, Stephen J. Sociologia das políticas educacionais e pesquisa crítico-social: uma revisão pessoal das políticas educacionais e da pesquisa em política educacional. Currículo sem Fronteiras, Porto Alegre, v. 6, n. 2, p. 10-32, 2006.

COSTA, Antonia Flávia Moraes da A. Prática do coordenador pedagógico no contexto da Escola de Tempo Integral: desafios da educação integral e integrada. 2015. Dissertação (Mestrado em Educação) Universidade Federal do Piauí, 2015. Disponível em:

http://leg.ufpi.br/subsiteFiles/ppged/arquivos/files/Disserta $\% C 3 \% A 7 \% C 3 \% A 30 \% 20 V E R S \%$ C3\%83O \%20DE\%20ENTREGA\%20com\%20DATA.pdf. Acesso em: 20 abr. 2018.

DOMINGUES, Isaneide. O coordenador pedagógico e a formação contínua do docente na escola. São Paulo: Cortez, 2014.

DUARTE, Alexandre William Barbosa; OLIVEIRA, Dalila Andrade. Valorização profissional docente nos sistemas de ensino de Minas Gerais e Pernambuco. Práxis Educacional. Vitória da Conquista v. 10, n. 17 p. 67-97, jul./dez. 2014. Disponível em:

http://www.gestrado.net.br/images/publicacoes/92/AlexandreDalila_ValorizacaoProfissionalD ocenteMGePE.pdf. Acesso em: 25 de março de 2017.

FACCI, M. G. D. Valorização ou esvaziamento do trabalho do professor? Um estudo crítico-comparativo da teoria do professor reflexivo, do construtivismo e da psicologia vigotskiana. Campinas:

Autores Associados, 2004.

IMBERNÓN, Francisco. Formação docente e profissional: formar-se para a mudança e a incerteza. 9. ed. São Paulo: Cortez, 2011.

MENDES, Juliana Camila Barbosa. Coordenação Pedagógica: especulações sobre um espaço relacional. In: FRANGELLA, Rita de Cássia Prazeres (org.). Políticas curriculares, coordenação pedagógica e escola: desvios, passagens e negociações. Curitiba: CRV, 2016.

MIZIARA, Leni Aparecida Souto et al. Coordenador pedagógico: limites e desafios no contexto do OBEDUC. An. Sciencult. Paranaíba. v. 6, n. 1, p. 263-276, 2015. Disponível em: https://anaisonline.uems.br/index.php/sciencult/article/viewFile/3108/3167. Acesso em: 12 jul. 2018.

ORLANDI, Eni. Análise de Discurso: Princípios e procedimentos. Campinas: Pontes Editores, 2013.

PERNAMBUCO. Secretaria de Educação e Esportes de. Parâmetros para a Educação Básica do Estado de Pernambuco. Parâmetros de Formação Docente: Ciências Naturais, Biologia, Física Química, Matemática. 2014. Disponível em:

http://www.educacao.pe.gov.br/portal/upload/galeria/7801/ParametrosdeFormacaoDocente_ Vol3.pdf. Acesso em: 23 abr. 2017.

PLACCO, Vera M. N. S. Formação de professores: o espaço de atuação do coordenador pedagógico-educacional. In: AGUIAR, M. A. S.; FERRETO, N. S. C. (org.). Para onde vão a orientação e a supervisão educacional? Campinas, SP: Papirus, 2002. p. 95-106.

PLACCO, Vera M. N. S; ALMEIDA, Laurinda Ramalho de (org.). O coordenador pedagógico: provocações e possibilidades de atuação. São Paulo: Loyola, 2012. 
PLACCO, Vera M. N. S; ALMEIDA, Laurinda Ramalho de (org.). O coordenador pedagógico no espaço escolar: articulador, formador e transformador. São Paulo: Loyola, 2015.

RAMOS, Daniela K.; WATERKEMPER, Sandra Regina. O coordenador pedagógico e as relações interpessoais no contexto escolar: entre percepções e ações. Dialogia. São Paulo, n. 17, p. 159-171, jan./jun. 2013. Disponível em:

http:/ / periodicos.uninove.br/index.php?journal=dialogia\&page $=$ article\&op $=$ view\&path $\% 5 \mathrm{~B} \% 5$ $\mathrm{D}=4014$. Acesso em: 23 abr. 2018.

RANGEL, Iguatemi Santos. A formação continuada de professores da educação infantil no sistema municipal de ensino de vitória: um confronto entre as propostas oficiais e a opinião dos professores. PPGE-UFES. In: REUNIÃO ANUAL DA ANPED, 29., Anais... Caxambu/MG, 2006.

SILVA, L. G. A. da; SAMPAIO, C. L. Trabalho e Autonomia do Coordenador Pedagógico no Contexto das Políticas Públicas Educacionais Implementadas no Estado de Goiás. Ensaio: Aval. Pol. Públ. Educ, Rio de Janeiro, v. 23, n. 89, out.-dez. 2015, p. 964-983. Disponível em: http://www.scielo.br/pdf/ensaio/v23n89/1809-4465-ensaio-23-89-0964.pdf. Acesso em: 14 abr. 2017.

SILVA, José Felix da. A formação continuada para professores dos anos iniciais em redes de ensino no Agreste pernambucano: um olhar sobre as ações voltadas ao ensino de matemática. 2013. Dissertação (Mestrado) - Programa de Pós-Graduação em Educação Contemporânea, PPGEDUC, Centro Acadêmico do Agreste, Universidade Federal de Pernambuco, Caruaru, 2013.

Recebido em: 22 maio. 2019 / Aprovado em: 25 nov. 2019

\section{Cite como}

QUEIROZ, Lindinalva Ferreira de; LINS, Carla Patrícia Acioli. Escuta de professores e professoras sobre os sentidos da atuação do coordenador pedagógico na formação continuada centrada na escola. Dialogia, São Paulo, n. 33, p. 99-114, set./dez. 2019. Disponível em: https://doi.org/10.5585/Dialogia.n33.13958.

\footnotetext{
${ }^{1}$ A partir deste trecho, todas as vezes que nos referirmos à Análise de Discurso, utilizaremos a sigla A.D.

2 Referem-se ao modo como os sujeitos se subjetivam em determinado lugar.

3 Pernambuco no ranking nacional: $2012-8^{\circ}$ (22.765); $2013-8^{\circ}$ (21.642, -1.123); $2014-8^{\circ}(21.520,-122) ; 2015-7^{\circ}$ (22.624, +1.104); $2016-7^{\circ}(23.489,+865) ; 2017-7^{\circ}(23.896,+407)$. Disponivel em:

http://blogs.diariodepernambuco.com.br/esportes/2017/12/07/o-ranking-nacional-de-federacoes-em-2017-compernambuco-em-7o-lugar/. Acesso em: 5 abr. 2018.

4 “"...] Sobrevivência e vantagem competitiva na economia da educação [...] esforço dedicado à produção das fabricações pessoais e institucionais” (BALL, 2005, p. 545).
} 